\title{
Conservation genetics of a wide-ranged temperate snake: same species, different locations, and different behaviour
}

jean-pierre vacher ( $\boldsymbol{\sim}$ jpvacher@gmail.com )

CEFE: Centre d'Ecologie Fonctionnelle et Evolutive https://orcid.org/0000-0002-9655-183X

Eric Graitson

Natagora

Julie Cauwenbergh

Universität Basel: Universitat Basel

Sylvain Ursenbacher

Universität Basel: Universitat Basel

\section{Research Article}

Keywords: Hectotherms, Population genetics, Gene flow, Connectivity, Fragmentation, Reptile conservation

Posted Date: February 25th, 2021

DOl: https://doi.org/10.21203/rs.3.rs-232447/v1

License: (c) (i) This work is licensed under a Creative Commons Attribution 4.0 International License. Read Full License

Version of Record: A version of this preprint was published at Conservation Genetics on October 27th, 2021. See the published version at https://doi.org/10.1007/s10592-021-01416-4. 


\section{Abstract}

Even though reptiles are threatened worldwide, few studies address their conservation, especially snakes. The goal of our study was to measure the genetic structure of a widely distributed temperate reptile, the smooth snake Coronella austriaca using eight microsatellite markers in two different areas at the core (Alsace, north-eastern France) and at the edge (Wallonia, southern Belgium) of its range. We sampled 506 individuals in 38 localities (respectively 10 and 28). Analysis of genetic structure conducted with a clustering method detected three clusters in Alsace, one group gathering all populations but two. In Wallonia, differentiation was observed on both sides of the Meuse river and in the Southern Ardenne region (southernmost sampling sites). Spatial autocorrelation analysis showed that individuals share parental relationship up to a distance of $2.8 \mathrm{~km}$ in Alsace and up to $10 \mathrm{~km}$ in Wallonia. Isolation by distance was detected in Wallonia but the distance explained a very limited part of the differentiation $(r=$ 0.033), whereas no isolation-by-distance pattern was detected in Alsace. Even though genetic differentiation between populations separated by large rivers, highways, or crop fields was detected, dispersal between populations seem currently sufficient to avoid any kind of genetic drift in both regions. These results are strongly contrasting with a previous study in England, suggesting sharp local variation of genetic structuring and diversification between location within the same species, probably related to the position in the distribution area and different densities.

\section{Introduction}

In the scope of the current biodiversity crisis, most studies on animal conservation focus on endangered and highly threatened species (Foden et al. 2013; Wagner et al. 2014; Howard et al. 2020; Loiseau et al. 2020). Still, getting to know how more common and widespread species react to different threats remains challenging (Kyek et al. 2017; Sánchez-Bayo and Wyckhuys 2019; Rosenberg et al. 2019). For example, comparing how populations at the core and at the edge of their distribution area manage changes induced on their environment such as habitat fragmentation, pollution, introduction of pathogens, might nonetheless be crucial in understanding how biodiversity can adapt to changes. And consequently how to adjust conservation practices that can also benefit to putative non-endangered species, or to threatened populations of wide-ranged species that occur at the edge of the range (Gill et al. 2007; Dudaniec et al. 2012; Peterman et al. 2013; Orme et al. 2019; Weihmann et al. 2019). One of the key aspects of understanding the potential of adaptation to changes in the environment is genetic diversity (Pauls et al. 2013). It has been shown for example that populations with a higher genetic diversity can adapt better to changes in the environment than populations with a lower genetic diversity (Desvars-Larrive et al. 2017). At the same time, populations at the edge of their range are likely to have a weaker genetic diversity, and therefore are more prone to decline (Böhme et al. 2007; Taubmann et al. 2011). In an ever and fast changing world, including common species in the conservation considerations becomes more and more important, as some of them can rapidly become endangered (Carrier and Beebee 2003; Gill et al. 2007; Studds et al. 2017; Kyek et al. 2017; Reading and Jofré 2020). Thus, it is crucial to understand the evolutionary mechanisms involved in such adaptations. According to the IUCN Red List, one of the major 
threats to terrestrial wildlife is the destruction of habitats (Pimm et al. 2014; IUCN 2020), which induces fragmentation and loss of connexion between populations. Small vertebrates such as reptiles are particularly sensitive to such disturbances, and it has been shown that some populations of common species are particularly exposed to fragmentation, and thus can become severely threatened (Driscoll 2004; Guiller 2009).

As amphibians, non-avian reptiles face declines at a global scale (Gibbons et al. 2000). For example, in Europe, about $20 \%$ of species are listed in the threatened categories of the IUCN (Cox and Temple 2009). All the more, several species of snakes are facing decline at a global scale, among which some are found in Europe (Reading et al. 2010). Fragmentation, alteration, and destruction of habitats are highlighted as the main threats to reptile populations in Europe (Corbett 1989; Cox and Temple 2009; Reading et al. 2010). These processes lead to isolation of populations and rupture in gene flow (Frankham et al. 2002; Dixo et al. 2009), and are often associated with a reduction of population size, genetic drift, and loss of genetic diversity (Frankham et al. 2002). Therefore, adaptation capacities of populations faced with biotic or abiotic events such as diseases, unusual climatic events, or pollution, become reduced and thus can speed up the decline process at a local level (Frankham et al. 2002). The cumulative effects of these factors can lead to extinctions of populations and, in the case of species with a rather limited range, to the extinction of species. In vertebrates, such rapid extinctions have been observed, for example within amphibians (Pounds and Crump 1994; Stuart et al. 2008; Collins and Crump 2009). Few studies have been carried out in order to assess the conservation status and the genetic structure of populations of snake species (Mullin and Seigel 2009). Still, snakes can be indicators of the level of fragmentation in a given landscape (Guiller and Legentilhomme 2006). Moreover, a limited number of studies were conducted on the same species but in different locations, in order to determine if species can react differently in different habitats or if their dispersal behaviour is fixed (Lane and Shine 2011). Consequently, evaluating the genetic structure within different regions in the same species could provide valuable information on the biology of the species, but also on how species behave in different environments.

Snakes are particularly sensitive to habitat fragmentation and direct destruction (Bonnet et al. 1999). Additionally, reptiles, and particularly snakes, are not often used as model species in conservation biology (Bonnet et al. 2002; Mullin and Seigel 2009). Therefore, we decided to examine a cryptic and rather poorly studied species given its wide range, the smooth snake, Coronella austriaca. Its distribution is rather well defined (Sillero et al. 2014), and a recent study suggest that the widely distributed taxon currently assigned to Coronella austriaca throughout Europe, western Asia and the Middle East might in fact be a complex of species with narrower distributions (Jablonski et al. 2019). The knowledge on its ecology and population dynamics increases during the last decades (Völkl and Käsewieter 2003; Dick and Mebert 2017; Graitson et al. 2020). For instance, a previous genetic study carried out on Coronella austriaca in England has demonstrated a strong impact of the geographic distance at a local scale (Pernetta et al. 2011), suggesting rather low dispersal capacities of the species. 
In this context, our study aimed at evaluating through genetic structure the magnitude of fragmentation on Coronella austriaca in two mainland environments with similar population densities but in different climates and locations within the core of the range of the species (Alsace, north-eastern France), and at the northern edge of the range (Wallonia, southern Belgium). The main questions we tackled were to assess the genetic relations of different population patches distributed throughout Alsace and Wallonia using microsatellite markers and evaluate if, as in England, the genetic isolation is clear between proximate populations. We hypothesised that as the smooth snake seems to be a poor disperser (Völkl and Käsewieter 2003; Pernetta et al. 2011; Dick and Mebert 2017), genetic structure should be marked even between geographically close populations. Also, we expect that even if the habitats and climate are somewhat different, the general pattern of genetic differentiation should be quite similar between regions.

\section{Material And Methods}

\section{Study area}

The study area comprised of two densely inhabited (roughly 220 inhabitants per $\mathrm{km}^{2}$ ) regions within the range of the Western 1 Coronella austriaca clade described by Jablonski et al. (2019): Alsace and Wallonia (Fig. 1). The sampling area in Alsace (north-eastern France) was located between $47^{\circ} 44^{\prime} \mathrm{N}$ and $48^{\circ} 3^{\prime} \mathrm{N}$ and $7^{\circ} \mathrm{E}$ and $7^{\circ} 27^{\prime} \mathrm{E}$, at elevations ranging from 200 to $500 \mathrm{~m}$ a.s.I (Fig. 1A). The sampling area in Wallonia (southern part of Belgium) covered a territory of about $10,000 \mathrm{~km}^{2}$. The latitude was comprised between $49^{\circ} 32^{\prime}$ and $50^{\circ} 38^{\prime} \mathrm{N}$, and the longitude between $4^{\circ} 26^{\prime}$ and $5^{\circ} 56^{\prime} \mathrm{E}$ (Fig. 1B). Altitudes of the studied habitats were comprised between 70 and $400 \mathrm{~m}$ a.s.I. Both regions contain several environmental elements that could induce habitat fragmentation, such as networks of motorways, roads, railways, wide surfaces of crop fields and vineyards (Alsace), and large surface of coniferous forest culture (Wallonia).

\section{Sampling design}

We collected a total of 506 DNA samples of Coronella austriaca throughout the whole study area in 38 different localities through buccal swabbing (Beebee, 2008; Pidancier et al., 2003). We collected 108 samples from 10 localities in Alsace (Fig. 1A) in 2009 and 2010 (Fig. 1A), and 398 samples in 28 localities in Wallonia between 2009 and 2011 (Fig. 1B). The two closest localities were separated by 2.6 $\mathrm{km}$, and the two most distant ones were separated by $85 \mathrm{~km}$. Snakes were found either by sight or with the use of artificial shelters $(70 \mathrm{~cm} \times 70 \mathrm{~cm}$ dark rubber plates in Alsace and of various materials in Wallonia). In order to avoid double sampling, a photograph of the pileus (dorsal side of the head) of each specimen captured enabled individual recognition on the field (Sauer 1994, 1997).

\section{Laboratory methods}

DNA was extracted using the QIAGEN DNeasy Blood \& Tissue kit (QIAGEN ${ }^{\circledR}$ ). Then, the following microsatellite loci specifically developed for the smooth snake were amplified by PCR: Ca16, Ca19, Ca30, Ca40, Ca43, Ca45, Ca612, Ca63 and Ca66 following the PCR conditions suggested by Bond et al. (2005). 
Forward dyed primers were used in order to analyse them with an automatic sequencer (AB3130xI Applied Biosystem). Allele lengths were then read with the software PEAK SCANNER v.1.0 (Applied Biosystem).

\section{Data analysis}

Each locus was first examined for null allele occurrence with MICRO-CHECKER v.2.2.3 (Van Oosterhout et al. 2004) for each sampling site and both regions separately. Loci showing a high probability $(p>0.05)$ of null alleles were discarded from the dataset. For each retained locus, we estimated allele frequency, observed and expected heterozygosity $\left(H_{O}, H_{E}\right)$ with GeneAlEx v6.503 (Peakall and Smouse 2006), whereas allelic richness $\left(A_{R}\right)$, intrapopulation structuration $\left(F_{I S}\right)$ and population differentiation $\left(F_{S T}\right)$ were evaluated with FSTAT v.2.9.3.2 (Goudet 1995). Genetic comparison between sampling sites were conducted with an ANOVA (with and without locus or population as factor) in R v3.6.3 (R Development Core Team 2016). We also performed a hierarchical structural analysis of gene diversity (AMOVA) to assess the molecular variance among sampling sites, among individuals and within individuals with GenAIEx, again for each region separately. We evaluated population subdivision for both region with a Bayesian clustering approach implemented in the software GENELAND v4.0.3 (Guillot et al. 2005). This method can be used to infer the number of genetic clusters (K) from the individual genotype distributed dataset in a spatial framework. We first performed five independent MCMC runs with $\mathrm{K}$ ranging from 1 to 10 for the Alsace region and from 1 to 30 for Wallonia, with the following parameters: 500000 MCMC iterations, 5000 thinning, maximum rate of Poisson process fixed at 100, uncertainty attached to spatial coordinates fixed to $0.2 \mathrm{~km}$. Then, we ran the MCMC model 100 times with the same parameters, five times first to determine the best $\mathrm{K}$ value and the sixth simulation was conducted with the best $\mathrm{K}$ value only as suggested by Guillot et al. (2005). From the last simulations, we selected the 10 runs with the highest mean logarithm value of posterior probability, and calculated the posterior probability of population membership for each pixel of the spatial domain for each of these 10 runs, using a burnin of $10 \%$. The number of pixels was set to 100 for the $X$ axis and 350 for the $Y$ axis for the Alsace region and respectively 350 and 350 for Wallonia, in order to avoid having two sampling sites in the same pixel. Finally, we computed posterior probability of population membership for each pixel of the spatial domain and the modal population of each individual. We then ran again standard population genetic analysis based on the number of populations inferred with GENELAND by calculating pairwise $F_{S T}$ and $F_{I S}$ with FSTAT, and tested the significance of the inferred structure by performing an AMOVA with GenAIEX.

For each region, we tested isolation of sampling sites by distance (IBD) with a Mantel test (Mantel 1967) by confronting corrected genetic differentiation $\left[F_{S T}\left(1-F_{S T}\right)\right]$ with the log values of the geographic distances between each sampling site (Rousset 1997). This test was implemented in $\mathrm{R}$ with the mantel.rtest function from the ade4 package (Dray and Dufour 2007) and 10000 repetitions. We combined the results of the IBD for both regions and also from the UK with the data included in the article of Pernetta et al. (2011). In addition, we performed a spatial autocorrelation analysis separately for both regions using SPAGeDI v.1.3 (Hardy and Vekemans 2002) in order to determine correlation between geographic distances and genetic relatedness measured by Moran's I-statistic (Moran 1950; Sokal and 
Wartemberg 1983). We assigned geographic coordinates for each locality. Distance classes were chosen in order to provide similar numbers of pairwise comparisons for each class, separately for each region.

\section{Results}

\section{Null alleles and genotypic disequilibrium}

We detected the presence of a probable null allele in Alsace for Ca30, due to an excess of homozygosity. Therefore, Ca30 was discarded from our following analyses that were consequently conducted with eight microsatellites markers (Ca16, Ca19, Ca40, Ca43, Ca45, Ca612, Ca63 and Ca66).

We detected an excess of homozygosity in Wallonia in Ca40 and Ca45, suggesting the presence of null alleles for these two markers. Moreover, genetic disequilibrium was significant between Ca43 and Ca612, as well as between Ca43 and Ca16. We consequently used only six microsatellite markers (Ca16, Ca19, Ca30, Ca612, Ca63 and Ca66) for this dataset.

\section{Genetic variation and diversity}

The number of alleles varied from 2 (Ca63) to 17 (Ca40) in Alsace (Table 1) and from 3 (Ca63) and 19 (Ca34) in Wallonia (Table 2). Globally, the allelic richness seems a bit higher in Alsace, even if four markers were different between both dataset (Ca30, Ca40, Ca43 and Ca45). The expected heterozygosity was also slightly higher in the Alsace region, even if the observed heterozygosity is similar. However, $A_{R}$ $H_{O}$ or $H_{E}$ were not significantly different between regions when considering the five similar loci in both populations, even when considering locus or populations as cofactors (for all $P>0.189$ ).

Table 1: Genetic variation across the sampled populations of Coronella austriaca in Alsace. $n$ : number of snakes genotyped per locus; Ar: allelic richness based on min. sample size of 4 diploid individuals; $H_{O}$ : observed heterozygosity; $H_{E}$ : expected heterozygosity; $F_{S T}$ : mean genetic differentiation; $F_{I S}$ : heterozygote deficit within populations. Bold indicates that the value is significant. 


\begin{tabular}{lcccccc} 
Population & $n$ & $A r$ & $H_{O}$ & $H_{E}$ & $F_{S T}$ & $F_{I S}$ \\
\hline Pop1 & 6 & 3.35 & 0.54 & 0.56 & 0.100 & 0.044 \\
Pop2 & 17 & 3.60 & 0.69 & 0.67 & 0.088 & -0.048 \\
Pop3 & 19 & 3.43 & 0.58 & 0.65 & 0.093 & 0.086 \\
Pop4 & 14 & 3.46 & 0.64 & 0.69 & 0.066 & 0.072 \\
Pop5 & 12 & 3.56 & 0.59 & 0.64 & 0.055 & 0.060 \\
Pop6 & 6 & 3.45 & 0.54 & 0.64 & 0.080 & 0.156 \\
Pop7 & 8 & 4.00 & 0.64 & 0.73 & 0.042 & 0.114 \\
Pop8 & 11 & 3.36 & 0.57 & 0.64 & 0.095 & 0.112 \\
Pop9 & 10 & 3.57 & 0.51 & 0.67 & 0.028 & 0.210 \\
Pop10 & 5 & 3.56 & 0.50 & 0.71 & 0.062 & 0.292 \\
\hline
\end{tabular}

Table 2: Genetic variation across the sampled populations of Coronella austriaca in Wallonia. n: number of snakes genotyped per locus; Ar: allelic richness based on min. sample size of 4 diploid individuals; $H_{O}$ : observed heterozygosity; $H_{E}$ : expected heterozygosity; $F_{S T}$ : mean genetic differentiation; $F_{I S}$ : heterozygote deficit within populations. Bold indicates that the value is significant. 


\begin{tabular}{lcccccc}
\hline Population & $n$ & $A r$ & $H_{O}$ & $H_{E}$ & $F_{S T}$ & $F_{I S}$ \\
\hline Pop1 & 10 & 3.26 & 0.55 & 0.64 & 0.056 & 0.182 \\
Pop2 & 5 & 3.49 & 0.60 & 0.60 & 0.066 & 0.106 \\
Pop3 & 5 & 3.61 & 0.77 & 0.66 & 0.038 & -0.057 \\
Pop4 & 7 & 3.17 & 0.49 & 0.54 & 0.127 & 0.166 \\
Pop5 & 15 & 2.88 & 0.60 & 0.59 & 0.112 & 0.009 \\
Pop6 & 17 & 3.62 & 0.68 & 0.67 & 0.071 & 0.008 \\
Pop7 & 21 & 3.31 & 0.64 & 0.64 & 0.083 & 0.021 \\
Pop8 & 14 & 3.44 & 0.59 & 0.67 & 0.069 & 0.152 \\
Pop9 & 13 & 3.17 & 0.50 & 0.58 & 0.127 & 0.174 \\
Pop10 & 9 & 3.19 & 0.45 & 0.57 & 0.096 & 0.271 \\
Pop11 & 28 & 2.95 & 0.49 & 0.54 & 0.157 & 0.113 \\
Pop12 & 13 & 3.23 & 0.66 & 0.61 & 0.089 & -0.032 \\
Pop13 & 21 & 3.14 & 0.67 & 0.64 & 0.093 & -0.027 \\
Pop14 & 10 & 3.22 & 0.68 & 0.62 & 0.061 & -0.04 \\
Pop15 & 11 & 2.94 & 0.41 & 0.56 & 0.112 & 0.312 \\
Pop16 & 12 & 2.92 & 0.60 & 0.57 & 0.073 & -0.014 \\
Pop17 & 9 & 2.51 & 0.42 & 0.49 & 0.143 & 0.213 \\
Pop18 & 19 & 3.19 & 0.54 & 0.63 & 0.083 & 0.178 \\
Pop19 & 6 & 2.87 & 0.50 & 0.58 & 0.098 & 0.231 \\
Pop20 & 24 & 3.34 & 0.53 & 0.61 & 0.090 & 0.159 \\
Pop21 & 33 & 3.35 & 0.53 & 0.64 & 0.113 & 0.184 \\
Pop22 & 21 & 3.24 & 0.60 & 0.63 & 0.062 & 0.102 \\
Pop23 & 7 & 3.80 & 0.46 & 0.67 & 0.044 & 0.398 \\
Pop24 & 15 & 2.76 & 0.43 & 0.56 & 0.100 & 0.275 \\
Pop25 & 11 & 2.78 & 0.57 & 0.55 & 0.097 & 0.031 \\
Pop26 & 8 & 3.31 & 0.60 & 0.61 & 0.071 & 0.087 \\
Pop27 & 16 & 3.25 & 0.73 & 0.63 & 0.111 & -0.133 \\
Pop28 & 18 & 3.30 & 0.64 & 0.62 & 0.078 & -0.002 \\
\hline & & & & & & \\
\hline
\end{tabular}

The FSTAT analysis revealed an overall mean $F_{S T}$ value of 0.075 in Alsace (pairwise comparisons min: -0.002; max: 0.15, Supplementary Table S1) and 0.114 in Wallonia (pairwise comparisons min: -0.044; max: 0.234; Supplementary Table S2). The AMOVA analysis revealed that only $7 \%(p=0.001)$ of the variance was explained by the differentiation among populations (variation among individuals $=11 \%, p=$ 0.001 ; variation within individuals $=82 \%, p=0.001$ ) in the Alsace region, whereas the respective proportions were $9 \%, 72 \%$ and $19 \%$ (all with a $p=0.001$ ) in Wallonia. 


\section{Genetic structure}

GENELAND always inferred three groups in Alsace: cluster 1 comprised 72 individuals and corresponded to sampling sites $1,4,5,6,7,8,9$, and 10; cluster 2 contained 17 individuals and corresponded to sampling site 3 ; and eventually cluster 3 contained 19 individuals and corresponded to sampling site 2 (Figs. 1A, S1, Table S1).

In Wallonia, GENELAND suggested five clusters as the best grouping number, but gathered all populations in only four groups: cluster 4 contained 203 individuals and corresponded to sampling sites 1-6, 10, 12$16,18,23-25$, and 27 ; cluster 5 containing 94 samples and grouping sampling sites $7-9,11$, and 28 ; cluster 6 containing 68 individuals and corresponding to sampling sites 17, 19,20, 22, and 26; cluster 7 containing 33 samples and only sampling site 21 (Figs. 1B, S2, Table S2).

\section{Population genetic analysis on the inferred populations}

In Alsace, we ran standard population genetic analysis based on the results of GENELAND, on the three groups inferred. The overall $F_{S T}$ value was $0.070(\mathrm{p}<0.05)$. In the first group (including 8 sampling sites), $F_{I S}$ was $0.163(\mathrm{p}<0.05)$. In the second group (sampling site 2$), F_{I S}$ was $-0.048(\mathrm{p}>0.05)$. In the third group (sampling site 3$), F_{I S}$ was $0.086(p>0.05)$. With this grouping, the AMOVA revealed that most of the variance was explained by the differentiation within individuals $(82 \%, P=0.001)$.

In Wallonia, the population genetic analysis based on the four groups of populations gathered by GENELAND indicated an overall $F_{S T}$ value of $0.050(\mathrm{p}<0.05)$, with respectively $F_{I S}$ values of $0.147,0.148$, 0.176 and 0.190 (all $p<0.05$ ) within the different groups. Following this grouping, $72 \%$ of the variance was explained by the differentiation within individuals and only $3 \%$ among groups.

\section{Isolation by distance and spatial autocorrelation}

Mantel's correlation test did not reveal any effect of IBD between the studied sites (Mantel test: $r=-0.023$; $P=0.86$; Fig. 2) in the Alsace region, but the distance was negatively correlated with the distance at the margin of statistical significance when tested within the first group obtained with GENELAND (Mantel test: $r=0.079 ; p=0.080$ ). In Wallonia, IBD was detected at the whole scale (Mantel test: $r=0.032 ; P=$ 0.0003; Fig. 2), but within the groups identified with GENEALEX, a significant signal of IBD was only present in the group5 (Mantel test: group4 $r=-0.007 ; P=0.730$; goup5: $r=0.389 ; P=0.032$; group6: $r=$ $0.121 ; P=0.173)$.

The spatial autocorrelation between Euclidian distance and relatedness (measured as Moran's index) was significant for the distance classes between 0 and $2.8 \mathrm{~km}$ for the Alsace region. This indicated that smooth snakes in Alsace are more related to each other within a distance of $2.8 \mathrm{~km}$. For Wallonia, this distance is even bigger, as a significant autocorrelation was detected up to a distance of $10 \mathrm{~km}$.

\section{Discussion}




\section{Genetic differentiation in Alsace and Wallonia}

Globally, the genetic differentiation between populations in both Alsace and Wallonia is limited or follow natural, geographical or historical isolation (River Meuse in Wallonia, or the southern part of the Ardennes). Indeed, as no or only weak isolation by distance was detected (opposite to the results in UK; Pernetta et al., 2011; see below), it is likely that other processes are influencing the genetic differentiation between populations, such as some landscape elements (e.g., rivers) or historical events (e.g., climate fluctuations) that we could not detect with this study.

In some specific cases, populations are more differentiated than expected based on the genetic pattern observed in both regions. In Alsace, the south-westernmost group (cluster 3, Fig. 1A) seems to be isolated from the others, according to GENELAND and presenting a significant pairwise $F_{S T}$ with all other sampling. Also, it has a negative $F_{I S}$ value (-0.048), which, though not significant, indicates a propensity to outbreeding. This result could be caused by a reduction of the size of this population, due to a recent isolation event, and thus conduction to some genetic drift. Indeed, this sampling site is located west and north of two main highways. These elements might represent recent physical barriers to gene flow. Similarly, other sub-populations included in cluster 1 separated by major highways or by large areas of crop fields also show high and significant $F_{S T}$ values (e.g., highways between pop4 and pop8; crop fields between pop4 and pop5; see Table 2). Therefore, it would then be possible that populations of $C$. austriaca located at the southwest of Alsace are isolated from the rest due to the fragmentation caused by highways. It has been shown that average sized and small species of snakes tend to avoid crossing roads (Andrews and Gibbons 2005) or are killed when trying to cross roads (Bonnet et al. 1999). Our results tend to suggest that it should be the case for $C$. austriaca, as highways could indeed constitute a strong barrier to gene flow if no underpasses are found along large sections of such roads.

In Wallonia, a significant but weak $(r=0.033)$ signal of isolation by distance was detected. Indeed, it could be related to the global structure detected with GENELAND, with the occurrence of four clusters, three of them representing well-separated regions [southern region (cluster 6); central region (cluster 4) and the edge of the central region (cluster 5)]. Even if some signal of IBD could be detected within clusters 5 and 6 , it was significant only for cluster 5 . Moreover, the grouping realised with GENELAND is not based on distances as sampling sites of clusters 4 and 5 are sometimes very close. This splitting is probably more related to historical reasons. For instance, the group6 gathered all the populations from the southern part of the Ardennes, where the species is not very common as habitats are cold and mainly composed of forests. We can hypothesise the differentiation between clusters 4 and 5 is resulting from the occurrence of the Meuse River. Indeed, all but one (sampling site 28) sampling sites from the group5 is on the north-western part of the Meuse River. Within group4, all sampling site except sampling site 3 are on the shore or south-eastern part of this river. The Meuse River is the largest river in Belgium; it probably acted as a barrier to the movement of $C$. austriaca for several centuries. Cluster 7 , that gathered individuals from the single sampling site 21 , does not present particular geographic barriers with other populations of the group5 that could explain its genetic differentiation. Local monitoring in the sampling 
site 21 highlighted a strong increase of individuals during the last years, with the lack of smooth snake 30 years ago (Graitson et al. 2012). We can consequently hypothesise that this population undergone a strong founder effect with the colonisation by a very limited number of individuals only 2-3 generations ago, which could explain the significant $F_{I S}$ value. Contrary to what is observed in Alsace, the difference between the groups does not seem to be explained by a barrier effect induced by motorways, which are nevertheless present in the sampled area, but more by geographical elements. We believe that the hilly terrain in Wallonia offers more possibilities to cross the motorways through underpasses.

Such a low genetic differentiation was unexpected, as strong differentiation was detected in several species of snakes with similar ecology requirements, even within putative interconnected habitat: for example, ecologically interconnected populations of Nerodia sipedon, an aquatic colubrid from North America, which has a similar home range as $C$. austriaca (between 1 and 4 ha), showed a marked genetic differentiation, maybe resulting from a high degree of philopatry (Prosser et al. 1999). For species with different life-history traits ('sit and wait' predators and strict capital breeders) but similar in size and shape, a high genetic structure was also observed within three viperids: Vipera berus in Western Europe (Ursenbacher et al. 2009), Vipera ursinii in Southern France (Ferchaud et al. 2011), and Sistrurus catenatus in the north of the United States and South of Canada (Gibbs et al. 1997). On the other hand, the genetic structure of a terrestrial elapid, Hoplocephalus bungaroides, in Australia, demonstrated a low genetic structure (Dubey et al. 2011), like for $C$. austriaca in Alsace. So we can assume that, if the barriers are limited, the smooth snake keeps populations interconnected over long distances, due to underestimated individual movement, but also a larger and more diffuse presence of the species in between recognised populations (see below).

\section{Comparison between regions}

Our study reveals a contrasting pattern of genetic structure among the same species in different studied regions, one located more to the core of the range, and the other to the edge of the range. Moreover, Pernetta et al. (2011) have demonstrated that isolation by distance is marked for smooth snake between population patches distributed in a small forest area in Southern England (highest distance between two patches $<6 \mathrm{~km}$; Pernetta et al., 2011). In this case, isolation by distance might rather be the result of the low dispersal capacities of the species, rather than the fragmentation of habitat, as the authors mentioned the occurrence of suitable habitats that could be used as corridors between population patches (Pernetta et al. 2011). Moreover, the density is probably lower in Southern England, conducting to a higher genetic drift and thus higher $F_{S T}$ values. This situation is rather different from what was observed in Alsace and in Wallonia. In Alsace where the overall $F_{S T}$ values were similar ( 0.075 vs. 0.078 in England), but where the sampled area was much wider (maximum distance between sampled sites $\approx 85$ $\mathrm{km}$ in Alsace vs. $<6 \mathrm{~km}$ in England) (Pernetta et al. 2011). In Wallonia, the $F_{S T}$ value is higher (0.114), but over an even larger distance (maximum distance between sampled sites $\approx 125 \mathrm{~km}$ ) and with the occurrence of at least four genetic groups. It is to note that the $F_{S T}$ values between the three studies did not result from the exact same set of genetic markers (2/8 were similar for the three studies; $3 / 8$ between Alsace or Wallonia and England), but the genetic diversity, number of alleles and allelic richness are 
similar between all loci, suggesting that the use of different markers would have only a limited impact on the comparison. Also, the effect of isolation by distance was significant in Southern England $(r=0.511$, $\mathrm{p}<0.05$ ), whereas no effect was detected in Alsace and only a weak significant signal in Wallonia (fig. 2). We expected to find a stronger effect of isolation in both Alsace and Wallonia due to the larger distances between populations if a similar genetic pattern as in England has been detected, which was not the case. This observed discrepancy obtained at a different scale should lead to further studies at the same spatial scale and with the same set of microsatellites in order to avoid artefacts due to large variation in distance between populations. However, the comparison of Pernetta et al. (2011) and this project clearly suggests that, within a species, genetic structure can strongly vary between habitats or regions. Such differences of genetic structure and diversity between regions have already been demonstrated in other groups, with a more marked genetic structure and lower diversity at the edge in comparison to the core of the distribution (Munwes et al. 2010; Dudaniec et al. 2012; Meeus et al. 2012; Ursenbacher et al. 2015). Therefore, it would be interesting to investigate the genetic structure of populations of Coronella austriaca in other parts of its distribution limits and in similar habitats (i.e., lowlands), in Scandinavia or in Western France for example, to detect if the dispersal behaviour varies in function of the positions within the distribution of the species or more due to local geographical elements.

Moreover, the studied populations in both regions are still large enough and rather widespread to avoid a strong genetic drift, as shown by the similar level of genetic diversity and limited $F_{S T}$ values (Table 1 and 2), contrary to the populations studied in England (Pernetta et al. 2011). Though our sampling pattern shows populations that are geographically separated (fig. 1), our results suggest that the dispersal capacities are underrated for this species. Preliminary capture-recapture data suggest that smooth snakes are rather philopatric in Alsace (J.P. Vacher, unpublished data), which is in accordance to what is known in the literature for this species and other temperate snakes (Völkl and Käsewieter 2003; Pattishall and Cundall 2008; Pernetta et al. 2011). Still, further studies on dispersal would be necessary to assess this question (Keogh et al. 2007), as most information on movement behaviour within this species concern movement within the home range and not actual dispersal (Clobert et al. 2012).

Smooth snakes have been found in a rather wide range of habitats and microhabitats in Alsace (Thiriet and Vacher 2010) and in Wallonia (Jacob et al. 2007; Graitson et al. 2020), such as dry grassland, heathlands within forests, peat bogs, rocky elements along roads, tracks, railways and dykes, river embankments, stone walls in vineyards, old buildings, and even in gardens. Even though the smooth snake is an elusive species and-we certainly tend to underestimate population sizes, our results also suggest that dispersal might also be underestimated, at least for some individuals (males or juveniles) and in mainland Europe, even if, locally, when the density is low or at the edge of the distribution area, the diversification could be strong. We think that further studies on its ecology, distribution, and population dynamics should be carried out to better understand the use of the landscape, the importance of dispersal on the population dynamics of this species, as well as the position in the distribution area or the density on its genetic diversification. 


\section{Declarations}

\section{Acknowledgements}

We are grateful to the following people for providing help on the field and in the lab: Nicolas Boileau, Gaël Fellet, Charles Huyttenhoven, Charlotte Mathelart, Barbara Meister, Victoria Michel, Daniel Muller, Eric Pellerint, Matthieu Raemy, Laurent Schwebelt, Jacques Thiriet. We also thank three anonymous referees for their useful comments that helped improve the quality of this article. We would like to dedicate this article to the memory of Laurent Schwebel, a dear friend and fellow naturalist who passed away in 2012 and whose help on the field was invaluable, and to the memory of Eric Pellerin who helped us collect data in Belgium.

Competing interest: The authors declare that they have no conflict of interest in the scope of this study.

Funding info: This study benefited of the support of the "Département de l'Etude du Milieu Naturel et Agricole du Service Public de Wallonie".

Author's contributions: JPV, EG, JC, and SU designed the study and wrote the manuscript. JPV did the field work in Alsace and the subsequent lab work. EG and JC did the field work in Wallonia. JPV, JC, and SU analysed the data.

Availability of data and material: All DNA samples from Alsace are deposited in the BEV collection in Montpellier (\#recodring in progress, accession numbers will be provided later for the publication\#). The DNA samples from Wallonia are deposited in the Natural History Museum Bern (\#recodring in progress, accession numbers will be provided later for the publication\#).

Animal research (ethics): Permits (no reference number provided) were delivered by the Prefect of Alsace to J.-P. Vacher, and by the department of Nature and Forest from Wallonia Public Service to E. Graitson for capture and handling of Coronella austriaca. Snakes were captured and released on spot right after sampling, no other tissue/blood collection has been performed other than buccal swabbing. A permit to drive on forest tracks in the Haut-Rhin department was issued to J.-P. Vacher by the National Forest Department (Mr. Pierrat, Mulhouse, France).

Consent to participate: All authors approved to participate to this study.

Consent to publish: All authors approved to the publication of this study.

\section{References}

1. Andrews KM, Gibbons JW (2005) How do highways influence snake movement? Behavioral responses to roads and vehicles. Copeia 2005:772-782. https://doi.org/10.1643/00458511(2005)005[0772:HDHISM]2.0.CO;2 
2. Böhme M, Schneeweiß N, Fritz U et al (2007) Small edge populations at risk: genetic diversity of the green lizard (Lacerta viridis viridis) in Germany and implications for conservation management. Conserv Genet 8:555-563

3. Bond JM, Porteous R, Hugues S et al (2005) Polymorphic microsatellite markers, isolated using a simple enrichment procedure, in the threatened smooth snake (Coronella austriaca). Mol Ecol Notes 5:42-44

4. Bonnet X, Naulleau G, Shine R (1999) The dangers of leaving home: Dispersal and mortality in snakes. Biol Conserv 89:39-50. https://doi.org/10.1016/S0006-3207(98)00140-2

5. Bonnet X, Shine R, Lourdais O (2002) Taxonomic chauvinism. Trends Ecol Evol 17:1-3. https://doi.org/10.1016/S0169-5347(01)02381-3

6. Carrier JA, Beebee TJC (2003) Recent, substantial, and unexplained declines of the common toad Bufo bufo in lowland England. Biol Conserv 111:395-399. https://doi.org/10.1016/S00063207(02)00308-7

7. Clobert J, Baguette M, Benton TG, Bullock JM (2012) Dispersal Ecology and Evolution. Oxford University Press

8. Collins JP, Crump ML (2009) Extinction in Our Times: Global Amphibian Decline. Oxford University Press

9. Corbett K (1989) Conservation of European Amphibians and Reptiles. Christopher Helm, London

10. Cox NA, Temple HJ (2009) European Red List of Reptiles

11. Desvars-Larrive A, Pascal M, Gasqui P et al (2017) Population genetics, community of parasites, and resistance to rodenticides in an urban brown rat (Rattus norvegicus) population. PLoS One 12:e0184015. https://doi.org/10.1371/journal.pone.0184015

12. Dick DCD, Mebert K (2017) Between housing and deep forest: Long-term population biology and dispersal of suburban Smooth snakes (Coronella austriaca). Zool Anz 270:98-106. https://doi.org/10.1016/j.jcz.2017.09.007

13. Dixo M, Metzger JP, Morgante JS, Zamudio KR (2009) Habitat fragmentation reduces genetic diversity and connectivity among toad populations in the Brazilian Atlantic Coastal Forest. Biol Conserv 142:1560-1569

14. Dray S, Dufour A-B (2007) The ade4 package: implementing the duality diagram for ecologists. J Stat Softw 22:1-20. https://doi.org/10.18637/jss.v022.i04

15. Driscoll DA (2004) Extinction and outbreaks accompany fragmentation of a reptile community. Ecol Appl 14:220-240

16. Dubey S, Sumner J, Pike DA et al (2011) Genetic connectivity among populations of an endangered snake species from southeastern Australia (Hoplocephalus bungaroides, Elapidae). Ecol Evol 1:218227. https://doi.org/10.1002/ece3.25

17. Dudaniec RY, Spear SF, Richardson JS, Storfer A (2012) Current and historical drivers of landscape genetic structure differ in core and peripheral salamander populations. PLoS One 7:e36769 
18. Ferchaud AL, Lyet A, Cheylan M et al (2011) High genetic differentiation among french populations of the orsini's viper (Vipera ursinii ursinii) based on mitochondrial and microsatellite data: Implications for conservation management. J Hered 102:67-78. https://doi.org/10.1093/jhered/esq098

19. Foden WB, Butchart SHM, Stuart SN et al (2013) Identifying the world's most climate change vulnerable species: A systematic trait-based assessment of all birds, amphibians and corals. PLoS One 8:e65427

20. Frankham R, Ballou JD, Briscoe DA (2002) Introduction to Conservation Genetics. Cambridge University Press

21. Gibbons JW, Scott DE, Ryan TJ et al (2000) The global decline of reptiles, déjà vu amphibians. Bioscience 50:653-666

22. Gibbs HL, Prior KA, Weatherhead PJ, Johnson G (1997) Genetic structure of populations of the threatened eastern massasauga rattlesnake, Sistrurus $c$. catenatus: evidence from microsatellite DNA markers. Mol Ecol 6:1123-1132

23. Gill J, Langston R, Alves JA et al (2007) Contrasting trends in two Black-tailed Godwit populations: a review of causes and recommendations. Wader Study Gr Bull 114:43-50

24. Goudet J (1995) Fstat version 1.2: a computer program to calculate Fstatistics. J Hered 86:485-486

25. Graitson E, Hussin J, Vacher J-P (2012) Synthèse de 24 années de suivi d'une communauté de reptiles typiques du nord de l'Europe. Bull la Société Herpétologique Fr 141:63-81

26. Graitson E, Ursenbacher S, Lourdais O (2020) Snake conservation in anthropized landscapes: considering artificial habitats and questioning management of semi-natural habitats. Eur J Wildl Res 66:39. https://doi.org/10.1007/s10344-020-01373-2

27. Guiller G (2009) Déclin et biologie d'une population de Zamenis longissimus (Laurenti, 1768) (Serpentes, Colubridae) en Loire-Atlantique. Bull la Société Herpétologique Fr 132:85-114

28. Guiller G, Legentilhomme J (2006) Impact des pratiques agricoles sur une population de Vipera berus (Linnaeus, 1758) (Ophidia, Viperidae) en Loire-Atlantique. Bull la Société Sci Nat l'Ouest la Fr Nouv série 28:73-81

29. Guillot G, Mortier F, Estoup A (2005) Geneland: a computer package for landscape genetics. Mol Ecol Notes 5:712-715. https://doi.org/10.1111/j.1471-8286.2005.01031.x

30. Hardy OJ, Vekemans X (2002) SPAGeDI: a versatile computer program to analyse spatial genetic structure at the individual or population levels. Mol Ecol Notes 2:618-620

31. Howard C, Flather $\mathrm{CH}$, Stephens PA (2020) A global assessment of the drivers of threatened terrestrial species richness. Nat Commun 11:1-10. https://doi.org/10.1038/s41467-020-14771-6

32. IUCN (2020) The IUCN Red List of Threatened Species. Version 2020-2. https://www.iucnredlist.org. Accessed 1 Oct 2020

33. Jablonski D, Nagy ZT, Avcı A et al (2019) Cryptic diversity in the smooth snake (Coronella austriaca). Amphibia-Reptilia 40:179-192. https://doi.org/10.1163/15685381-20181025 
34. Jacob J-P, Percsy C, Wavrin H de et al (2007) Amphibiens et Reptiles de Wallonie. Série Faune-FloreHabitats $n^{\circ} 2$. Aves - Raînne et Ministère de la Région wallone, Namur

35. Keogh JS, Webb JK, Shine R (2007) Spatial genetic analysis and long-term mark-recapture data demonstrate male-biased dispersal in a snake. Biol Lett 3:33-35

36. Kyek M, Kaufmann PH, Lindner R (2017) Differing long term trends for two common amphibian species (Bufo bufo and Rana temporaria) in alpine landscapes of Salzburg, Austria. PLoS One 12:e0187148-e0187148. https://doi.org/10.1371/journal.pone.0187148

37. Lane A, Shine R (2011) Intraspecific variation in the direction and degree of sex-biased dispersal among sea-snake populations. Mol Ecol 20:1870-1876. https://doi.org/10.1111/j.1365294X.2011.05059.x

38. Loiseau N, Mouquet N, Casajus N et al (2020) Global distribution and conservation status of ecologically rare mammal and bird species. Nat Commun 11:5071. https://doi.org/10.1038/s41467020-18779-w

39. Mantel N (1967) The detection of disease clustering and a generalized regression approach. Cancer Res 27:209-220

40. Meeus S, Honnay O, Jacquemyn H (2012) Strong differences in genetic structure across disjunct, edge, and core populations of the distylous forest herb Pulmonaria officinalis (Boraginaceae). Am J Bot 99:1809-1818

41. Moran PAP (1950) Notes on the continuous stochastic phenomena. Biometrika 37:17-23

42. Mullin SJ, Seigel RA (2009) Snakes. Ecology and Conservation. Cornell University Press

43. Munwes I, Geffe E, Roll U et al (2010) The change in genetic diversity down the core-edge gradient in the eastern spadefoot toad (Pelobates syriacus). Mol Ecol 19:2675-2689

44. Orme CDL, Mayor S, Anjos L, dos et al (2019) Distance to range edge determines sensitivity to deforestation. Nat Ecol Evol 3:886-891. https://doi.org/10.1038/s41559-019-0889-z

45. Pattishall A, Cundall D (2008) Spatial biology of northern watersnakes (Nerodia sipedon) living along an urban stream. Copeia 2008:752-762

46. Pauls SU, Nowak C, Bálint M, Pfenninger M (2013) The impact of global climate change on genetic diversity within populations and species. Mol Ecol 22:925-946. https://doi.org/10.1111/mec.12152

47. Peakall R, Smouse PE (2006) genalex 6: genetic analysis in Excel. Population genetic software for teaching and research. Mol Ecol Notes 6:288-295. https://doi.org/10.1111/j.14718286.2005.01155.x

48. Pernetta AP, Allen JA, Beebee TJC, Reading CJ (2011) Fine-scale population genetic structure and sex-biased dispersal in the smooth snake (Coronella austriaca) in southern England. Heredity 107:231-238

49. Peterman WE, Feist SM, Semlitsch RD, Eggert LS (2013) Conservation and management of peripheral populations: Spatial and temporal influences on the genetic structure of wood frogs (Rana sy/vatica) populations. Biol Conserv 158:351-358 
50. Pimm SL, Jenkins CN, Abell R et al (2014) The biodiversity of species and their rates of extinction, distribution, and protection. Science 80-:344:1246752

51. Pounds JA, Crump ML (1994) Amphibian declines and climate disturbance: The case of the golden toad and the harlequin frog. Conserv Biol 8:72-85

52. Prosser MR, Gibbs HL, Weatherhead PJ (1999) Microgeographic population genetic structure in the northern water snake, Nerodia sipedon sipedon detected using microsatellite DNA loci. Mol Ecol 8:329-333

53. R Development Core Team (2016) R: A Language and Environment for Statistical Computing. R Found. Stat. Comput. Vienna Austria

54. Reading C, Jofré G (2020) Smooth snake population decline and its link with prey availability. Amphibia-Reptilia 41:43-48

55. Reading CJ, Luiselli LM, Akani GC et al (2010) Are snake populations in widespread decline? Biol Lett $6: 777-780$

56. Rosenberg KV, Dokter AM, Blancher PJ et al (2019) Decline of the North American avifauna. Science 80-:366:120-124

57. Rousset F (1997) Genetic differentiation and estimation of gene flow F-statistics under isolation by distance. Genetics 145:1219-1228

58. Sánchez-Bayo F, Wyckhuys KAG (2019) Worldwide decline of the entomofauna: A review of its drivers. Biol Conserv 232:8-27. https://doi.org/10.1016/J.BIOCON.2019.01.020

59. Sauer A (1994) Methode zur Identifizierung der Schlingnatter (Coronella austriaca). Salamandra 30:43-47

60. Sauer A (1997) Fotografische Individualidentifikation und erste Ergebnisse zur Langzeitbeobachtung einer Schlingnatterpopulation (Coronella austriaca). Mertensiella 7:103-110

61. Sillero N, Campos J, Bonardi A et al (2014) Updated distribution and biogeography of amphibians and reptiles of Europe. Amphibia-Reptilia 35:1-31. https://doi.org/10.1163/15685381-00002935

62. Sokal RR, Wartemberg DE (1983) A test of spatial autocorrelation analysis using an isolation-bydistance model. Genetics 105:219-237

63. Stuart S, Hoffmann M, Chanson J et al (2008) Threatened Amphibians of the World. Lynx Edicions; IUCN; Conservation International. 758 pp., Barcelona, Spain, Gland, Switzerland, Arlington, Virginia, USA

64. Studds CE, Kendall BE, Murray NJ et al (2017) Rapid population decline in migratory shorebirds relying on Yellow Sea tidal mudflats as stopover sites. Nat Commun 8:1-7. https://doi.org/10.1038/ncomms14895

65. Taubmann J, Theissinger K, Feldheim KA et al (2011) Modelling range shifts and assessing genetic diversity distribution of the montane aquatic mayfly Ameletus inopinatus in Europe under climate change scenarios. Conserv Genet 12:503-515. https://doi.org/10.1007/s10592-010-0157-x 
66. Thiriet J, Vacher J-P (2010) Atlas de répartition des Amphibiens et Reptiles d'Alsace. BUFO, Colmar/Strasbourg

67. Ursenbacher S, Guillon M, Cubizolle H et al (2015) Postglacial recolonization in a cold climate specialist in western Europe: patterns of genetic diversity in the adder (Vipera berus) support the central-marginal hypothesis. Mol Ecol 24:3639-3651. https://doi.org/10.1111/mec.13259

68. Ursenbacher S, Monney J-C, Fumagalli L (2009) Limited genetic diversity and high differentiation among the remnant adder (Vipera berus) populations in the Swiss and French Jura Mountains. Conserv Genet 10:303-315

69. Van Oosterhout C, Hutchinson WF, Wills DP, Shipley P (2004) MICRO-CHECKER: software for identifying and correcting genotyping errors in microsatellite data. Mol Ecol Notes 4:535-538

70. VölkI W, Käsewieter D (2003) Die Schlingnatter. Laurenti Verlag, Bielefeld

71. Wagner N, Rödder D, Brühl CA et al (2014) Evaluating the risk of pesticide exposure for amphibian species listed in Annex II of the European Union Habitats Directive. Biol Conserv 176:64-70. https://doi.org/http://dx.doi.org/10.1016/j.biocon.2014.05.014

72. Weihmann F, Weihmann S, Weihmann T (2019) Conservation genetic analysis of a Central-European range-margin population of the yellow-bellied toad (Bombina v. variegata). Conserv Genet 20:557569. https://doi.org/10.1007/s10592-019-01156-6

\section{Figures}




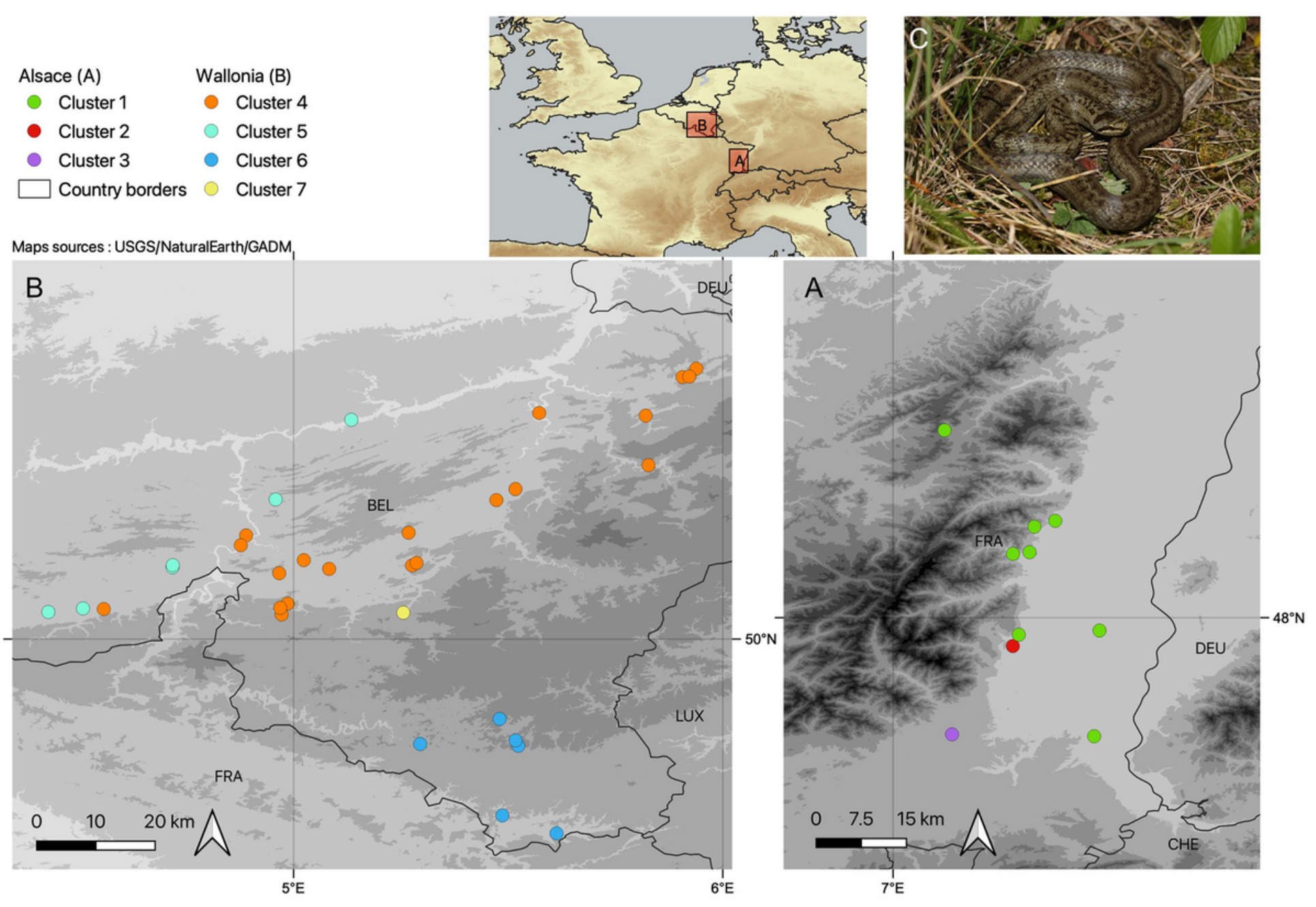

\section{Figure 1}

Sampling sites of the different populations of Coronella austriaca and GENELAND assignment of individuals in modal populations in (A) Wallonia and (B) Alsace. (C) Adult Coronella austriaca in Alsace (photograph by J.P. Vacher). Note: The designations employed and the presentation of the material on this map do not imply the expression of any opinion whatsoever on the part of Research Square concerning the legal status of any country, territory, city or area or of its authorities, or concerning the delimitation of its frontiers or boundaries. This map has been provided by the authors. 


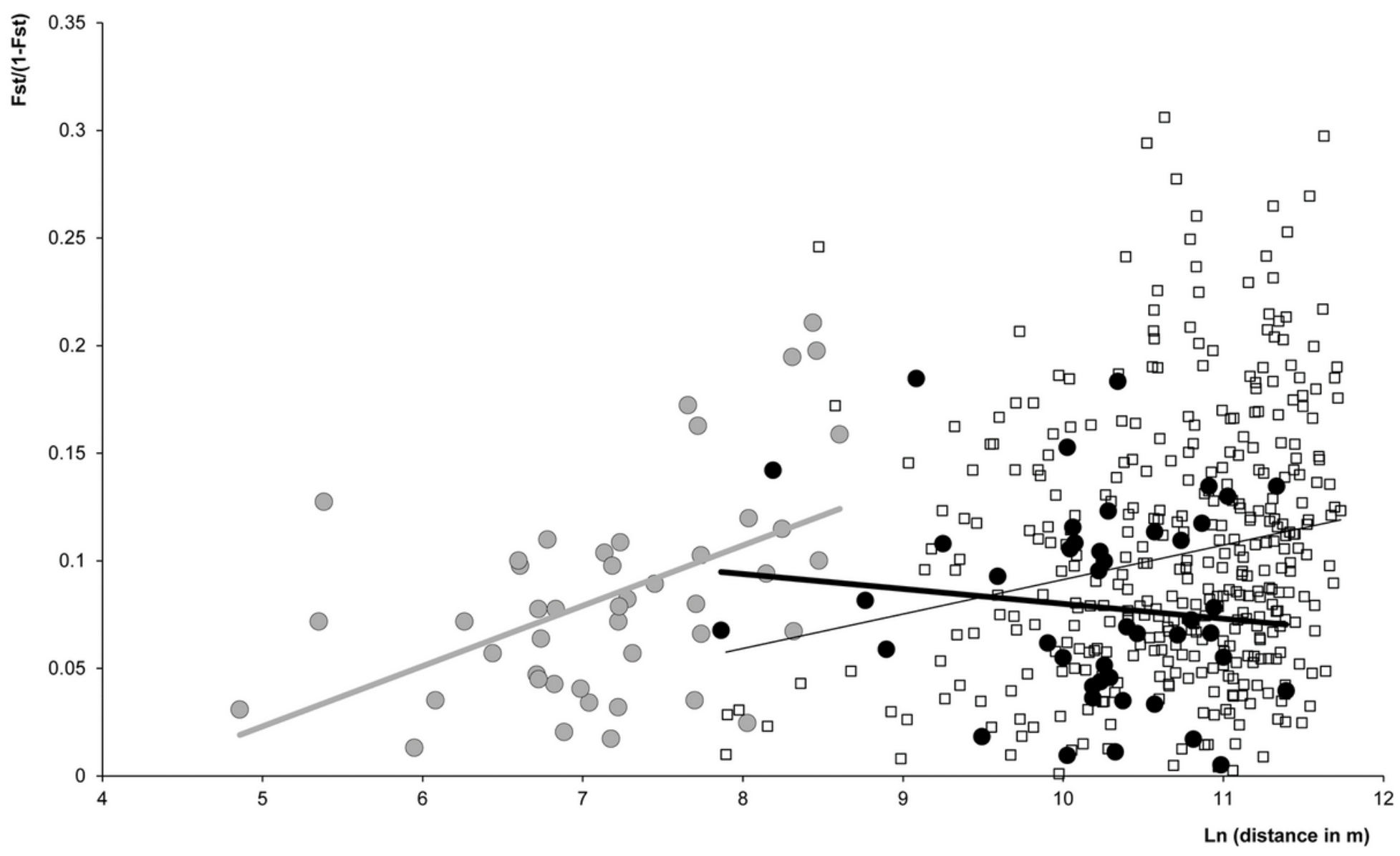

Figure 2

Isolation by distance $(\mathrm{m})$ for Coronella austriaca in Alsace (black dots; $r=-0.024 ; P=0.57$ ), Wallonia (white squares; $r=0.033 ; P=0.0003$ ) and Southern England (grey dots; $r=0.511, P=0.003$; data from Pernetta et al. 2011). Analyses for Alsace and Southern England were conducted with eight microsatellite markers, and with six microsatellites in Wallonia; only two of them were common between the three studies (Ca19 and Ca66). 
a)

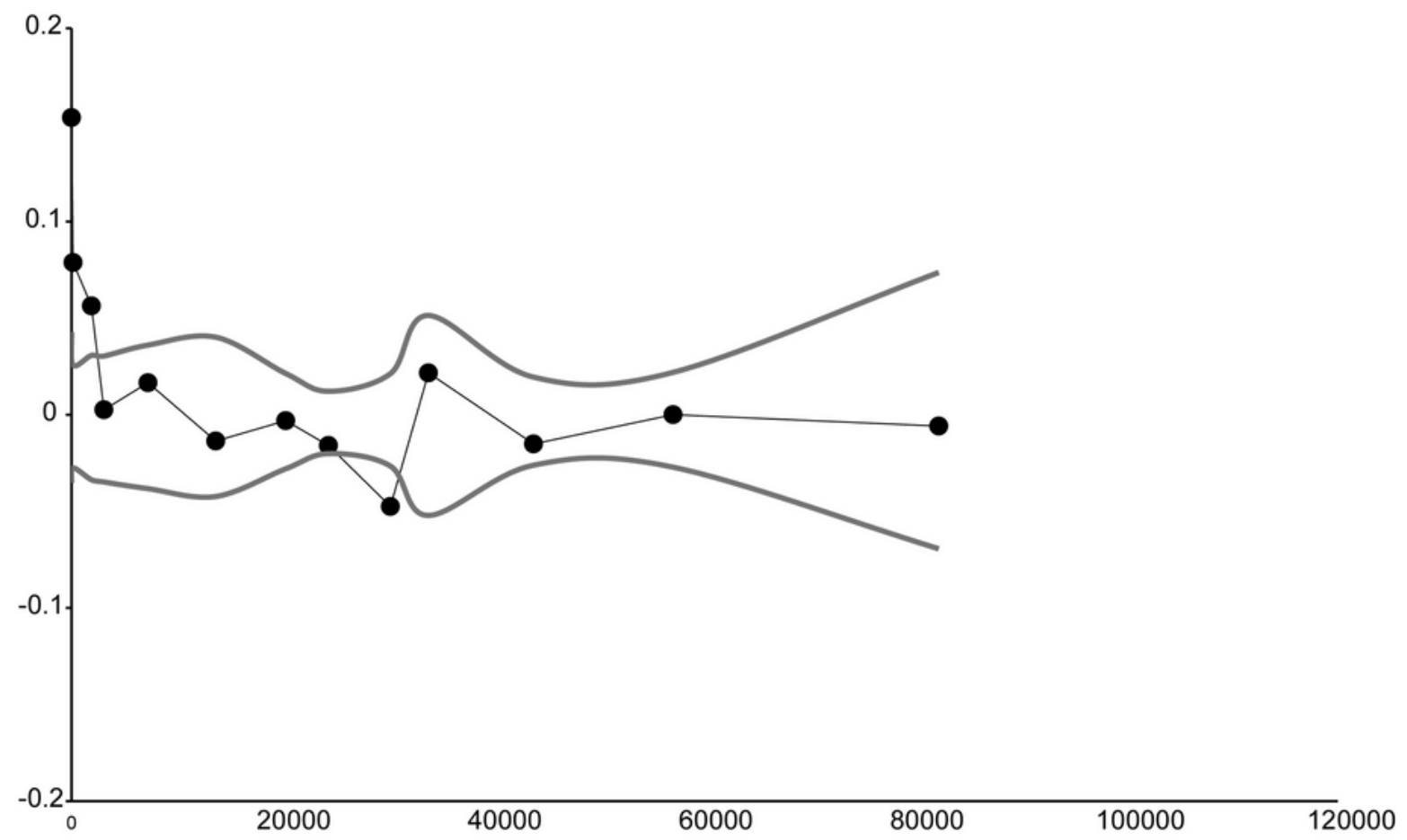

b)

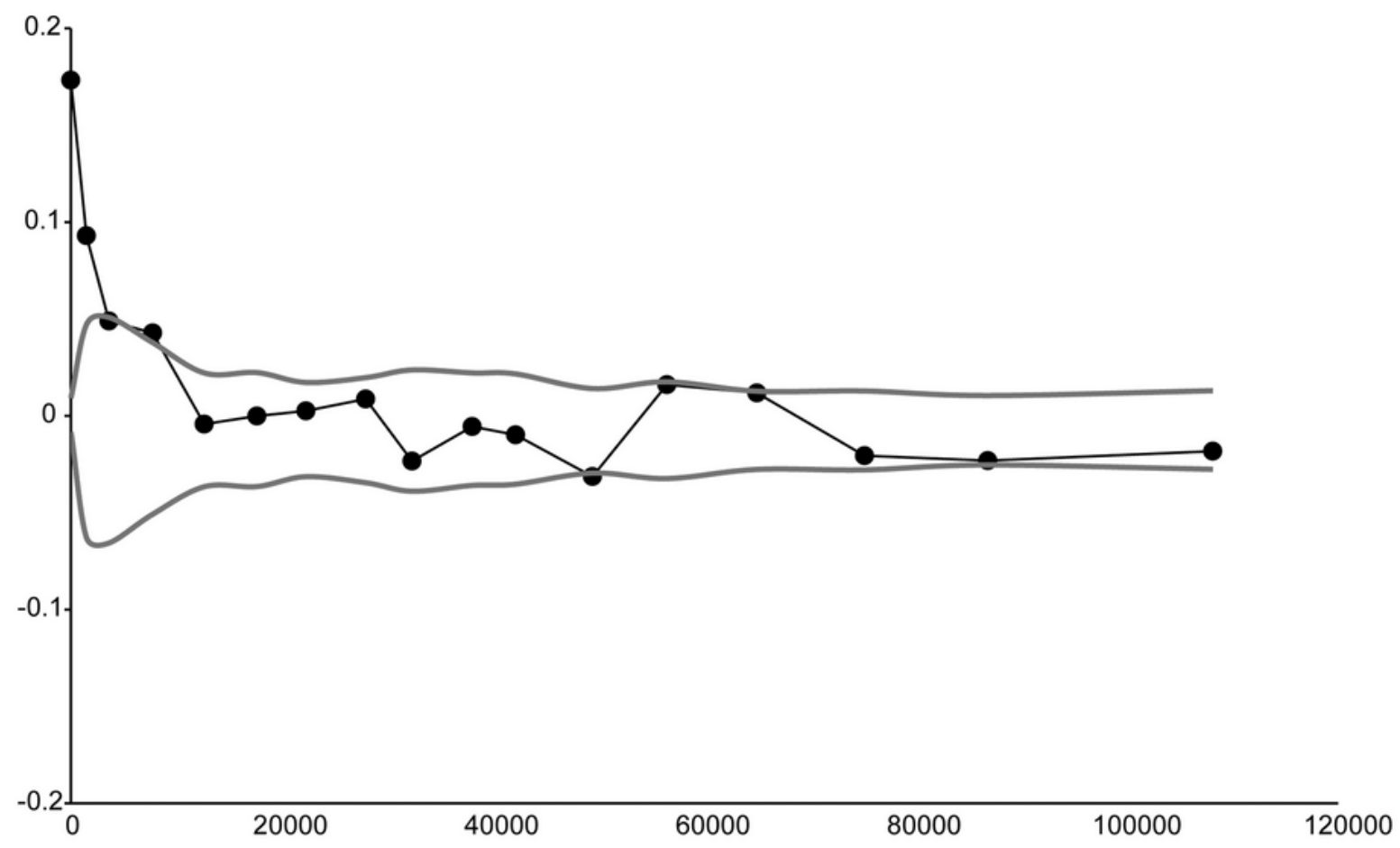

Figure 3

spatial autocorrelation in of Coronella austriaca a) in Alsace; b) in Wallonia calculated with SPAGEDI. The black lines represent the $95 \%$ confidence interval and * are present for significant autocorrelation.

\section{Supplementary Files}


This is a list of supplementary files associated with this preprint. Click to download.

- Supplementaryfile1.pdf

- Supplementaryfile2.pdf

- Supplementaryfile3.pdf 